\section{Consumption of Chlorhexidine and Mupirocin Across the Health System of the US Department of Defense (DOD) and the Incidence of the qac $A / B$ and mupA Genes in the DOD Facilities of the National Capital Region}

To THE EDitor - Despite heightened concern for increased resistance to mupirocin and chlorhexidine [1-4], reports that assess the relationship between consumption of the agents and genotypic resistance are scarce. We sought to determine if there were any significant trends in mupirocin and chlorhexidine consumption in the nationwide healthcare system of the US Department of Defense (DOD) and in a subset of DOD hospitals in the National Capital Region (DODNCR) that also conduct active surveillance for mupA and $q a c A / B$.

All consecutive methicillin-resistant Staphylococcus aureus (MRSA) isolated from clinical cultures in the DODNCR from 1 June 2014 to 31 December 2015 were prospectively included. Deduplication was based on 1 isolate per patient (the first). Isolates were tested for mup $A$ and $q a c A / B$ and 4 virulence-related genes using a multiplex polymerase chain reaction (PCR) assay, as previously described [5, 6]. Milliliters of chlorhexidine and mupirocin were tabulated for the DOD-NCR and the entire DOD as previously described [7]. Chlorhexidine consumption included liquid soaps and prescriptions for medicated wash cloths but not for oral rinse. Trend analysis was performed using generalized linear regression on SAS, version 12, adjusting for any seasonal variation in the data.

A total of 458 unique MRSA isolates (monthly average $=47$ ) were obtained from the DOD-NCR. Of these, $95.0 \%$ (435) were from infections (sterile sites or active wounds), with the remainder being colonizing (surface swabs of nares or intact skin). Twenty-five (5.5\%) were positive for $m u p A$. The monthly fraction of $m u p A$-positive isolates ranged from $0 \%$ to $25 \%$, with a mean of $7.2 \%$. We found only 3 positive $q a c A / B$ isolates $(0.6 \%)$. The monthly fraction of $q a c A / B$-positive isolates ranged from $0 \%$ to $11.1 \%$, with a mean of $0.9 \%$. The frequency of mupA or $q a c A / B$ positivity did not significantly increase over the observation period. Twenty-three isolates carried the sep gene (5.0\%) and 305 (67\%) carried the $p v l$ gene. $C f r$ and $e t A$ genes were not detected. Consumption trends varied by patient location (inpatient or ambulatory), stratification (nationwide or region), and hospital type (community hospital or tertiary care referral hospital; Table 1).

To our knowledge, we are the first to assess the relationships between genotypic resistance and consumptions of mupirocin and chlorhexidine, both locally-regionally and across a nationwide managed healthcare system. That such resistance did not increase despite increased consumption of mupirocin and chlorhexidine should not be taken as reassurance or a reason for relaxed vigilance of escalating resistance for several reasons.

First, like most hospitals, the facilities in this study use PCR for most surveillance to detect colonization. Therefore, very few

Table 1. Average Monthly Change in Mupirocin and Chlorhexidine Consumption in the Department of Defense (DOD) Healthcare System and the DOD National Capital Region Using Generalized Linear Regression

\begin{tabular}{|c|c|c|c|c|}
\hline & \multicolumn{2}{|l|}{ Mupirocin } & \multicolumn{2}{|c|}{ Chlorhexidine } \\
\hline & Average Monthly Change & $P$ Value & $\begin{array}{c}\text { Average } \\
\text { Monthly Change }\end{array}$ & $P$ Value \\
\hline \multicolumn{5}{|c|}{ DOD: All Hospitals in DOD including the DOD-NCR ${ }^{a}(n=280)$} \\
\hline \multicolumn{5}{|l|}{ Inpatient } \\
\hline g & 18.18 & $<.0001$ & & \\
\hline $\mathrm{mL}$ & & & 51.33 & .08 \\
\hline $\begin{array}{l}\text { Prescription for } \\
\text { cloths }\end{array}$ & & & 2.84 & .09 \\
\hline \multicolumn{5}{|l|}{ Outpatient } \\
\hline g & 894.55 & .13 & & \\
\hline $\mathrm{mL}$ & & & 704.07 & .04 \\
\hline \multicolumn{5}{|c|}{ Tertiary Care Referral Hospitals in DOD-NCR $(n=1)$} \\
\hline \multicolumn{5}{|l|}{ Inpatient } \\
\hline g & -3.90 & $<.0001$ & & \\
\hline $\mathrm{mL}$ & & & 0.09 & .15 \\
\hline \multicolumn{5}{|l|}{ Outpatient } \\
\hline g & 26.53 & .06 & & \\
\hline $\mathrm{mL}$ & & & 25.55 & .07 \\
\hline \multicolumn{5}{|c|}{ Community Hospitals and Ambulatory Clinics in DOD-NCR $(n=6)$} \\
\hline \multicolumn{5}{|l|}{ Inpatient } \\
\hline g & -0.01 & .88 & & \\
\hline $\mathrm{mL}$ & & & -0.81 & .22 \\
\hline \multicolumn{5}{|l|}{ Outpatient } \\
\hline g & 16.38 & .13 & & \\
\hline $\mathrm{mL}$ & & & 20.90 & .03 \\
\hline
\end{tabular}

A negative value indicates that the amount used decreased. Values in bold type are statistically significant.

Abbreviations: DOD, Department of Defense; DOD-NCR, DOD National Capital Region.

${ }^{a}$ All tertiary care referral hospitals and community hospitals and/or ambulatory clinics in the DOD combined. 
cultured surveillance/colonizing isolates are available for analysis. As mupirocin and chlorhexidine are used topically, the prevalence of mupA and $q a c A / B$ in the subgroup of colonizing isolates is likely higher. Although the DOD and DOD-NCR treat patients of all ages and races (including neonates and elderly), is widely geographically dispersed, and no close-quarter housing units (barracks) are used in the DOD-NCR, these findings may not be generalizable to other populations. Finally although mupirocin and chlorhexidine resistance did not increase in our study or the REDUCEMRSA trial [4], there is new concern that exposure to chlorhexidine might be associated with colistin resistance [8].

\section{Notes}

Disclaimer. The views expressed in the manuscript are solely those of the authors and are not to be construed as official or representing those of the US Department of Defense.

Financial support. This work was supported by the Presidential Initiative: Combating Antibiotic Resistant Bacteria and the Global Emerging Infections Surveillance and Response System. The funders had no role in the collection, analysis, or reporting of data and the preparation of the manuscript.

Potential conflicts of interest. All authors: No reported conflicts of interest. All authors have submitted the ICMJE Form for Disclosure of Potential Conflicts of Interest. Conflicts that the editors consider relevant to the content of the manuscript have been disclosed.

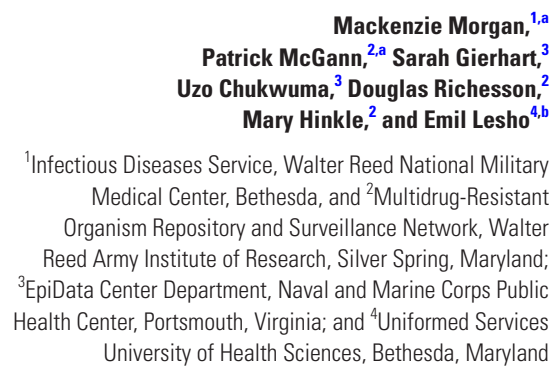

\section{References}

1. Suwantarat N, Carroll KC, Tekle T, et al. High prevalence of reduced chlorhexidine susceptibility in organisms causing central line-associated bloodstream infections. Infect Control Hosp Epidemiol 2014; 35:1183-6.

2. Lee AS, Macedo-Vinas M, François $P$, et al. Impact of combined low-level mupirocin and genotypic chlorhexidine resistance on persistent methicillin-resistant Staphylococcus aureus carriage after decolonization therapy: a case-control study. Clin Infect Dis 2011; 52:1422-30.
3. Warren DK, Prager M, Munigala S, et al. Prevalence of qacA/B genes and mupirocin resistance among methicillin-resistant Staphylococcus aureus (MRSA) isolates in the setting of chlorhexidine bathing without mupirocin. Infect Control Hosp Epidemiol 2016; 37:590-7.

4. Hayden MK, Lolans $\mathrm{K}$, Haffenreffer $\mathrm{K}$, et al Chlorhexidine and mupirocin susceptibility of methicillin-resistant Staphylococcus aureus isolates in the REDUCE-MRSA trial. J Clin Microbio 2016; 54:2735-42.

5. McGann P, Kwak YI, Summers A, Cummings JF, Waterman PE, Lesho EP. Detection of qacA/B in clinical isolates of methicillin-resistant Staphylococcus aureus from a regional healthcare network in the eastern United States. Infect Contro Hosp Epidemiol 2011; 32:1116-9.

6. Mc Gann P, Milillo M, Kwak YI, Quintero R, Waterman PE, Lesho E. Rapid and simultaneous detection of the chlorhexidine and mupirocin resistance genes $q a c A / B$ and $m u p A$ in clinical isolates of methicillin-resistant Staphylococcus aureus. Diagn Microbiol Infect Dis 2013; 77:270-2.

7. Lesho EP, Clifford RJ, Chukwuma U, et al. Carbapenem-resistant Enterobacteriaceae and the correlation between carbapenem and fluoroquinolone usage and resistance in the US military health system. Diagn Microbiol Infect Dis 2015; 81:119-25.

8. Wand ME, Bock LJ, Bonney LC, Sutton JM Mechanisms of increased resistance to chlorhexidine and cross-resistance to colistin following exposure of Klebsiella pneumoniae clinical isolates to chlorhexidine. Antimicrob Agents Chemother 2016; 61:e01162-16

${ }^{a} \mathrm{M}$. M. and P. M. contributed equally to this work

bPresent affiliation: Infectious Diseases Unit, Rochester Regional Health, New York.

Correspondence: E. Lesho, 1425 Portland Avenue, Rochester NY 14621 (carolinelesho@yahoo.com)

Clinical Infectious Diseases ${ }^{\circledR} \quad$ 2017;64(12):1801-2

(C) The Author 2017. Published by Oxford University Press for the Infectious Diseases Society of America. This is an Open Access article distributed under the terms of the Creative Commons Attribution-NonCommercial-NoDerivs licence (http://creativecommons.org/licenses/by-nc-nd/4.0/), which permits non-commercial reproduction and distribution of the work, in any medium, provided the original work is not altered or transformed in any way, and that the work is properly cited. For commercial re-use, please contact journals.permissions@oup.com DOI: $10.1093 / \mathrm{cid} / \mathrm{cix} 276$

\section{Potential Limitations of a Very Short Course of Antimicrobial Therapy for Ventilator- Associated Pneumonia}

To THE EDITOR-We read with great interest the study by Klompas et al suggesting that a very short course of antimicrobial therapy (1-3 days) might not be associated with a higher risk of ventilator or hospital death in patients with suspected ventilator-associated pneumonia (VAP), compared with a longer course [1]. We discuss some potential limitations of the study.

The authors based the study on their observation that three-quarters of patients treated for VAP "most likely did not have it," pointing to the lack of specificity of the currently existing VAP diagnosis process. However, the process used by the authors to identify VAP is even less specific as it only compiled a modification of ventilatory settings (inspired fraction of oxygen and positive end expiratory pressure), the utilization of a diagnosis procedure (endotracheal aspirate or bronchoalveolar lavage), and an antimicrobial order. No clinical or chest radiographic criteria were used [2]. No information regarding the colony-forming units per milliliter threshold to differentiate bacterial infection from simple colonization was considered. Thus, no differentiation between VAP, ventilator-associated tracheobronchitis (VAT), or atelectasis was achievable and it may be that this study merely reflects that $>3$ days of antimicrobial therapy was futile in treating VAT or atelectasis.

Moreover, the retrospective design of this study prevents us from identifying whether antimicrobial therapy was given for a new VAP episode, the continuation of a previous treatment, or another indication. The authors could neither determine whether empiric antimicrobial therapy was appropriate or not. Indeed, this could introduce a bias when discussing the relationship between duration of treatment and the outcomes. Finally, the majority of the identified bacteria corresponded to oral flora not representative of usual VAP microbial spectrum.

Taken together, these limitations detach the study results from the real-life management of patients and may alter the clinical relevance of the authors' conclusions.

We would also like to point out methodological issues in the statistical analyses. First, there may be an issue in the way the 2 groups were compared in the survival analysis. While the authors presented all their results as a comparison between 2 durations of antimicrobial therapy (1-3 days vs $>3$ days of antibiotics), the Methods section suggests that the 2 groups were actually based on the effective duration of antibiotics. However, such a duration is unknown at baseline and should be included in the 